\title{
Tracking Quantum Dot-Tagged Calcium Channels at Vertebrate Photoreceptor Synapses: Retinal Slices and Dissociated Cells
}

\author{
Aaron J. Mercer ${ }^{1,2}$ and Wallace B. Thoreson ${ }^{3,4}$ \\ ${ }^{1}$ Departments of Molecular and Integrative Physiology, University Of Michigan, Ann Arbor, \\ Michigan \\ ${ }^{2}$ Department of Internal Medicine, Division of Metabolism, Endocrinology and Diabetes, \\ University Of Michigan, Ann Arbor, Michigan \\ ${ }^{3}$ Departments of Ophthalmology and Visual Sciences, University of Nebraska Medical \\ Center, Omaha, Nebraska \\ ${ }^{4}$ Departments of Pharmacology and Experimental Neuroscience, University of Nebraska \\ Medical Center, Omaha, Nebraska
}

\begin{abstract}
At synapses in the central nervous system, precisely localized assemblies of presynaptic proteins, neurotransmitter-filled vesicles, and postsynaptic receptors are required to communicate messages between neurons. Our understanding of synaptic function has been significantly advanced using electrophysiological methods, but the dynamic spatial behavior and real-time organization of synapses remains poorly understood. In this unit, we describe a method for labeling individual presynaptic calcium channels with photostable quantum dots for single-particle tracking analysis. We have used this technique to examine the mobility of L-type calcium channels in the presynaptic membrane of rod and cone photoreceptors in the retina. These channels control release of glutamate-filled synaptic vesicles at the ribbon synapses in photoreceptor terminals. This technique offers the advantage of providing a real-time biophysical readout of ion channel mobility and can be manipulated by pharmacological or electrophysiological methods. For example, the combination of electrophysiological and single-particle tracking experiments has revealed that fusion of nearby vesicles influences calcium channel mobility and changes in channel mobility can influence release. These approaches can also be readily adapted to examine membrane proteins in other systems. Curr. Protoc. Neurosci. 62:2.18.1-2.18.23. (C) 2013 by John Wiley \& Sons, Inc.
\end{abstract}

Keywords: single particle tracking $\bullet$ L-type calcium channels $\bullet$ ribbon synapse • membrane diffusion

\section{INTRODUCTION}

Transmission of chemical signals between neurons requires a precisely orchestrated series of interactions between intracellular and membrane-bound proteins at the synapse. Typically, a presynaptic neuron releases neurotransmitter-filled vesicles when a depolarizing stimulus opens voltage-gated calcium channels in the synaptic terminal. The influx of calcium causes membrane-bound SNARE proteins to intertwine with SNARE proteins on synaptic vesicles, resulting in membrane fusion and the release of a vesicle's contents into the synaptic cleft. Much of our understanding about the details of synaptic communication has come from electrophysiological methods or anatomical techniques using fixed tissue, but approaches have been developed to monitor the dynamic movements of proteins involved in synaptic transmission in real-time. Techniques such as fluorescence 
recovery after photobleaching (FRAP; UNIT 2.17) and fluorescence resonance energy transfer (FRET; UNIT 5.22) offer insights into the behavior of populations of membrane-bound proteins. However, these methods cannot be used to look at the behavior of individual proteins, are dependent on the trafficking of synaptic proteins and lipids, and use fluorophores that can photobleach during extended periods of imaging. Thus, the development of quantum dot (QD) technology in the mid-1990s was rapidly adopted by neurobiologists to study membrane protein behavior. QDs are small (30 to $40 \mathrm{~nm}$ ) semiconductor molecules that can be engineered to fluoresce at different wavelengths and are remarkably photostable.

The photostability and small size of QDs make them ideal for studying the behavior of individual membrane-bound proteins, as the mobility of membrane-bound proteins can be imaged on a time scale of minutes to hours if necessary. While the images of individual QDs are blurred by the microscope's diffraction limit, one can fit the QD fluorescence profile with a Gaussian function to determine its location with a pointing accuracy that approaches the QD core diameter $(<10 \mathrm{~nm})$. Therefore, the position of an individual QD-labeled protein can be tracked with an accuracy that far exceeds the microscope's diffraction limit. To examine the membrane mobility of presynaptic L-type $\mathrm{Ca}^{2+}(\mathrm{Cav})$ channels that regulate vesicle release at the synapses of vertebrate photoreceptors, we developed a single-particle tracking technique to attach QDs through an antibody-based intermediary to an extracellular $\mathrm{Ca}_{\mathrm{v}}$ channel subunit. The attachment of antibodies and QDs to $\mathrm{Ca}_{\mathrm{V}}$ channels in living tissue requires an extracellular domain that can be selectively recognized by a primary antibody. The only extracellular domains of pore-forming $\alpha_{1}$ subunits of L-type $\mathrm{Ca}_{\mathrm{V}}$ channels are small loops between transmembrane segments (Catterall, 2000), whereas the accessory $\alpha_{2} \delta$ subunit is almost entirely extracellular (Bauer et al., 2010). We therefore attached QDs to calcium channels at photoreceptor synapses by using a primary antibody that targets the extracellular domain of the $\alpha_{2} \delta_{4}$ subunit, the major $\alpha_{2} \delta$ subunit in retina (Wycisk et al., 2006; Mercer et al., 2011a).

In this unit, we describe preparation of the Ambystoma tigrinum retinal tissue model (Basic Protocol 1), standard immunohistochemical attachment of QDs to Cav channels (Basic Protocol 2), and the optical configuration used for imaging and analysis of the trajectories of single QDs (Basic Protocol 3). Support protocols describe construction of the retinal slice perfusion chamber (Support Protocol 1), preparation of dissociated retinal tissue (Support Protocol 2), important control experiments (Support Protocol 3), and immunohistochemical processing of fixed retinal tissue (Support Protocol 4). The basic and support protocols provide a framework for further QD-based studies in the retina and can be adapted for use with other CNS, muscle and endocrine tissues.

BASIC PROTOCOL 1

\section{Tracking Calcium Channel Movements}

2.18.2

\section{PREPARATION OF THE AMBYSTOMA TIGRINUM RETINAL MODEL}

The tiger salamander (Ambystoma tigrinum) has been used as a model system for the study of retinal physiology for over forty years because of the robust nature of the tissue and the relatively large size of individual retinal neurons (Jakway and Riss, 1972; Lasansky, 1973; Wu, 1987). Attaching QDs to neurons in living retinal tissue requires a long incubation period of $\sim 4 \mathrm{hr}$; therefore, a robust preparation is important. Dissection of Ambystoma tigrinum retinal tissue requires some technical expertise, and it may take practice to master some of these techniques.

NOTE: All protocols involving vertebrate animals must first be reviewed and approved by an Institutional Animal Care and Use Committee (IACUC), following officially approved procedures for the care and handling of laboratory animals. Animals used for the studies described in this protocol were approved by the University of Nebraska Medical Center Institutional Animal Care and Use Committee. 
Dow Corning vacuum grease

HEPES-buffered amphibian extracellular saline solution, pH 7.8 (HAESS; see recipe), $4^{\circ} \mathrm{C}$

Adult aquatic tiger salamanders, male or female, 18 to $25 \mathrm{~cm}$ in length (Kons Scientific or Charles D. Sullivan Co., http://www.researchamphibians.com)

Plastic perfusion chamber (Support Protocol 1)

$25 \times 75$-mm microscope slides

Filter paper (type AAWP, $0.8 \mu \mathrm{m}$ pores; Millipore)

Linoleum tissue-dissecting block

Cotton balls

Heavy shears or small animal guillotine

Binocular dissecting microscope

Microsurgical tools (e.g., Word Precision Instruments)

$2 \times 12 \mathrm{~cm}$-long forceps with $0.08 \times 0.04 \mathrm{~mm}$ tips

$10.5 \mathrm{~cm}$-long fine-tip spring Vannas scissors, $3 \mathrm{~mm}$ blades

$10.5 \mathrm{~cm}$-long curved fine-tip spring Vannas scissors

Microscalpel

Razor blade tissue chopper (e.g., Stoelting Tissue Slicer 51425)

Razor blades (Ted Pella, cat. no. 121-6)

\section{Set up perfusion chamber}

A comprehensive description of the slice preparation with a diagram of the retinal chamber has been published in the Journal of Visualized Experiments (JoVE; Van Hook and Thoreson, 2012; http://www.jove.com/video/50007/simultaneous-whole-cell-recordingsfrom-photoreceptors-second-order? status $=a 52013 \mathrm{k}$ ).

1. Use vacuum grease to attach a $25 \times 75-\mathrm{mm}$ microscope slide to the base of the plastic perfusion chamber.

Vacuum grease provides a water-tight seal to prevent HAESS from leaking out through the base of the perfusion chamber.

2. Place two lines of grease parallel to the direction of superfusate flow to form a narrow lane in which to place the retinal slices.

It is also recommended to place a small piece of Kimwipe near the superfusate outlet line of the chamber to adjust and maintain steady HAESS flow during experiments.

3. Attach a piece of Millipore filter paper $(5 \times 10 \mathrm{~mm})$ to the surface of the microscope slide with two small beads of vacuum grease at either edge.

4. Place a small cotton ball onto a linoleum block for tissue dissection. Saturate the cotton with ice-cold HAESS.

\section{Animal euthanasia and cranial hemisection}

5. Remove one salamander from a $10^{\circ} \mathrm{C}$ aquarium and grasp firmly using a paper towel.

The cold temperature prevents the animals from metamorphosing into land-phase salamanders and also provides a base level of anesthesia prior to cranial decapitation.

6. With your free hand, use the heavy shears or small animal guillotine to swiftly decapitate the salamander. Sagitally hemisect the head and then cut off the lower jaw.

7. Place one cranial/eye section on a dampened paper towel in the refrigerator at $4^{\circ} \mathrm{C}$.

This eye can be used for a second dissection, if desired. 
8. Set the other cranial/eye section onto the HAESS-saturated cotton ball on the tissuedissecting block.

\section{Enucleate the Ambystoma tigrinum eye}

9. Under the dissecting microscope, use straight Vannas scissors to free the front of the eye from the orbit by cutting the skin that surrounds the eye.

When handling the eye during these procedures, take care to avoid puncturing the sclera and damaging the retina.

10. Pull the eye forward and enucleate it by cutting the optic nerve and extraocular muscles behind the eye.

11. Dispose of the salamander skull and place the eye back on the HAESS-saturated cotton ball.

12. Using fine, curved Vannas scissors, carefully trim off any excess connective tissue and orbital fat attached to the back of the eye.

13. Use the tip of a fine scalpel to make a small incision in the center of the cornea.

14. Using the curved Vannas scissors, extend the incision out to the ora serrata. Remove the iris and cornea after completing a circumferential incision around the ora serrata.

We recommend making a single incision and then rotating the eye by moving the underlying cotton ball before making another incision.

Do not extend the cut all the way into the sclera, as this can cause retinal detachment and damage.

15. Remove the iris and cornea by pulling them sideways out of the eyecup (typically, the lens comes out of the eyecup at the same time; if not, grasp the lens and remove it sideways out of the eyecup, too).

Pull the lens sideways, not straight up and out of the eyecup, since vitreal fibers attached to the lens can cause traction isolation of the retina.

\section{Eyecup sectioning and retinal tissue mounting}

16. Place the enucleated eyecup into a few drops of HAESS, anterior side up.

17. Break a double-edged razor blade in half. Use one half of the blade to cut the eyecup into quarters.

18. With forceps, grasp the back of the sclera and invert a piece of eyecup onto the still dry piece of $5 \times 10-\mathrm{mm}$ filter paper.

Avoid damaging the retinal tissue with the forceps. If possible, avoid using the eyecup section containing the optic nerve, since this can make it difficult to isolate the retina from the sclera and retinal pigment epithelium. The optic nerve is visible as a white circular point central to the posterior portion of the eyecup.

19. Use forceps to very gently press the sclera and retina against the filter paper.

20. Submerge the piece of eyecup with a few drops of ice-cold HAESS. Carefully peel away the sclera/choroid/retinal pigment epithelium to isolate the retina onto the filter paper.

21. If the retina does not appear to have adhered tightly to the filter paper, wick away the HAESS with a Kimwipe. Drain HAESS away from the edges of the filter paper and the retina to pull the retina more firmly down onto the filter paper. Do not touch the retina itself with the Kimwipe. Add a few drops of HAESS to ensure that the retina has adhered to the filter paper. If the retina has not adhered, repeat this step.

\section{Tracking Calcium Channel Movements}

\subsection{4}


22. Fill the perfusion chamber with ice-cold HAESS.

\section{Tissue slicing and positioning}

23. Place the perfusion chamber on the tissue chopper so that the filter paper and retina are beneath the razor blade, with the long side of the filter paper parallel to the long edge of the razor blade.

24. Press the razor blade on the slicer arm firmly through the filter paper and retina.

When the blade slices through the filter paper and retinal tissue, it should make a faint click as the blade strikes the glass. You may wish to remove the first strip of filter paper using the fine forceps to confirm that the blade has made a clean cut.

25. Continue sectioning the entire retina and filter paper in $125-\mu \mathrm{m}$ strips by advancing the stage with the Vernier micrometer.

26. Transfer the retinal slices, one at a time, to the "lane" of grease through which the perfusate will flow, using the following steps. Grasp one edge of the filter paper strip and separate it from the remaining strips. Lift the filter paper and adherent slice of retina slightly, then move the chamber beneath the retina so that the slice is above the central channel. Place one edge of the filter paper into one bead of grease. Then, press the other edge into the other bead of grease.

Be sure not to remove the retinal slices from the superfusate, since exposing the cut edges of the retinal slice to air can damage the cells.

27. As the strips of filter paper are placed in the two lanes of grease, rotate the slices $90^{\circ}$ so that the cut surface of the retina is visible from above and the photoreceptors face the incoming superfusate flow line. Press the cut edge of the filter paper flat against the base of the chamber.

When properly positioned, one should be able to see the stratified layers of the retina with the dissecting microscope.

28. Use a Kimwipe or paper towel to remove excess HAESS from the outer parts of the perfusion chamber, but leave fluid in the central channel and do not remove the HAESS from the retinal slices.

\section{IMMUNOHISTOCHEMICAL ATTACHMENT OF QDS TO L-TYPE Cav CHANNELS}

Basic Protocol 2 outlines the steps for attaching QDs to individual Cav channels by binding QDs via antibodies to the extracellular $\alpha_{2} \delta_{4} \mathrm{Cav}$ channel subunit (Qin et al., 2002). This strategy combines antigenic specificity with a strong biotin-streptavidin bond to label Cav channels directly with QDs. Expression of transgenic biotinylated proteins of interest can expedite the labeling process (Bates et al., 2006), but the utility of our method lies in the fact that antibody-based QD targeting can be readily adapted to study membrane proteins in a variety of tissues. Commercial kits can be used to pre-biotinylate primary antibodies, or users may opt to purchase QD-conjugated secondary antibodies. These strategies can shorten the incubation times described below. Our strategy adapts approaches developed for the labeling of neurotransmitter receptors (Bannai et al., 2006) by using a two-antibody system to target $\mathrm{Ca}_{\mathrm{V}}$ channels for single-particle tracking (SPT). The QD binding strategy is illustrated schematically in Figure 2.18.1. Figure 2.18.2A shows an example of a photoreceptor terminal in the outer plexiform layer (OPL) of a retinal slice labeled by a QD. Figure 2.18.2B shows a $\mathrm{Ca}_{V}$ channel labeled on the terminal of an isolated rod. 


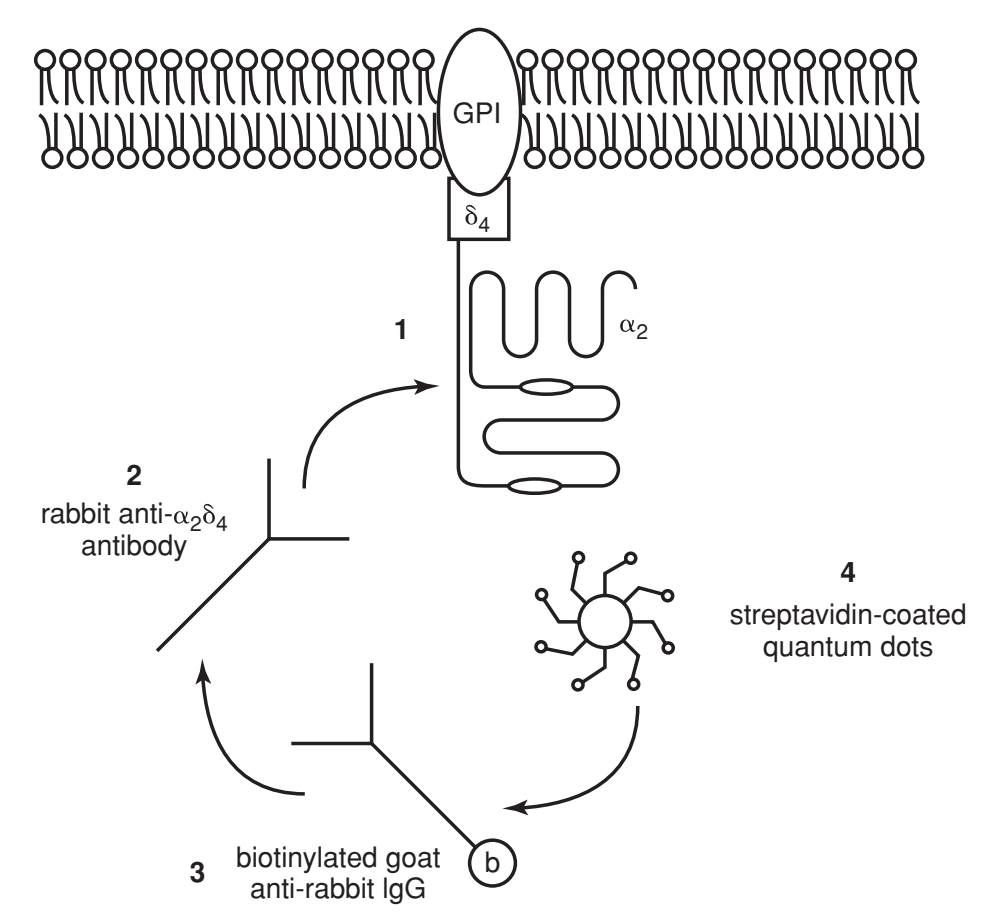

Figure 2.18.1 Binding strategy to attach QDs to extracellular $\alpha_{2} \delta_{4} \mathrm{Ca}$ channel subunits. QDs are attached to the extracellular $\alpha_{2}$ arm of $\mathrm{Ca}_{V} \alpha_{2} \delta_{4}$ subunits (1) by first attaching a rabbit anti-human $\alpha_{2} \delta_{4}$ antibody for $3 \mathrm{hr}$ at $4^{\circ} \mathrm{C}(2)$ to recognize the epitope Ac-KVSDRKFLTPEDEASVC-amide (Qin et al., 2002). Slices are next incubated for $1 \mathrm{hr}$ at $4{ }^{\circ} \mathrm{C}$ with a goat anti-rabbit biotinylated antibody (3). The biotin domain on the secondary antibody forms a strong covalent bond with streptavidincoated QDs (4), which are attached by incubation for $15 \mathrm{~min}$ at room temperature. Note that In this schematic we represent the $\alpha_{2} \delta_{4}$ subunit as a glycophosphotidylinositol (GPI)-anchored protein. Although studies have yet to resolve the full structure of $\mathrm{Ca}_{v} 1.4$ channel-associated $\alpha_{2} \delta_{4}$ subunits, other $\alpha_{2} \delta$ subunits that associate with L-type $\mathrm{Ca}_{v}$ channels are GPI-anchored proteins (Bauer et al., 2010; Davies et al., 2010). We speculate that $\alpha_{2} \delta_{4}$ subunits may have a similar structure and orientation at photoreceptor synapses.

NOTE: Success with this technique requires proper titration of each antibody to achieve appropriate QD labeling. If too many targets are labeled, it is difficult to distinguish individual $\mathrm{Ca}_{\mathrm{V}}$ channels. Furthermore, it is theoretically possible for a single QD to bind multiple secondary antibodies and for an individual antibody to bind simultaneously to two antigens. If too few channels are labeled, the many hours spent preparing the tissue and applying antibodies with QDs will waste the better part of a day. We describe dilutions used in our studies that were optimized to label only a handful of Cav channels in the retina model. Dilutions of antibodies for the study of other tissue systems or membrane proteins must be determined empirically.

\section{Materials}

Plastic perfusion chamber with retinal tissue (Basic Protocol 1) or slide with dissociated retinal tissue

HEPES-buffered amphibian extracellular saline solution (HAESS), $4^{\circ} \mathrm{C}$

Bovine serum albumin (BSA; Sigma-Aldrich, cat. no. A9418)

Primary antibody: rabbit anti- $\alpha_{2} \delta_{4}$ antibody (Qin et al., 2002)

Secondary antibody: goat anti-rabbit biotinylated antibody (Jackson ImmunoResearch, cat. no. 111-065-003)

Qdot 525 streptavidin conjugate $(1 \mu \mathrm{M}$; Invitrogen, cat. no. Q10141MP)

Humidified chamber: large petri dish with the perfusion chamber placed at the center and damp paper towels at the periphery 
A

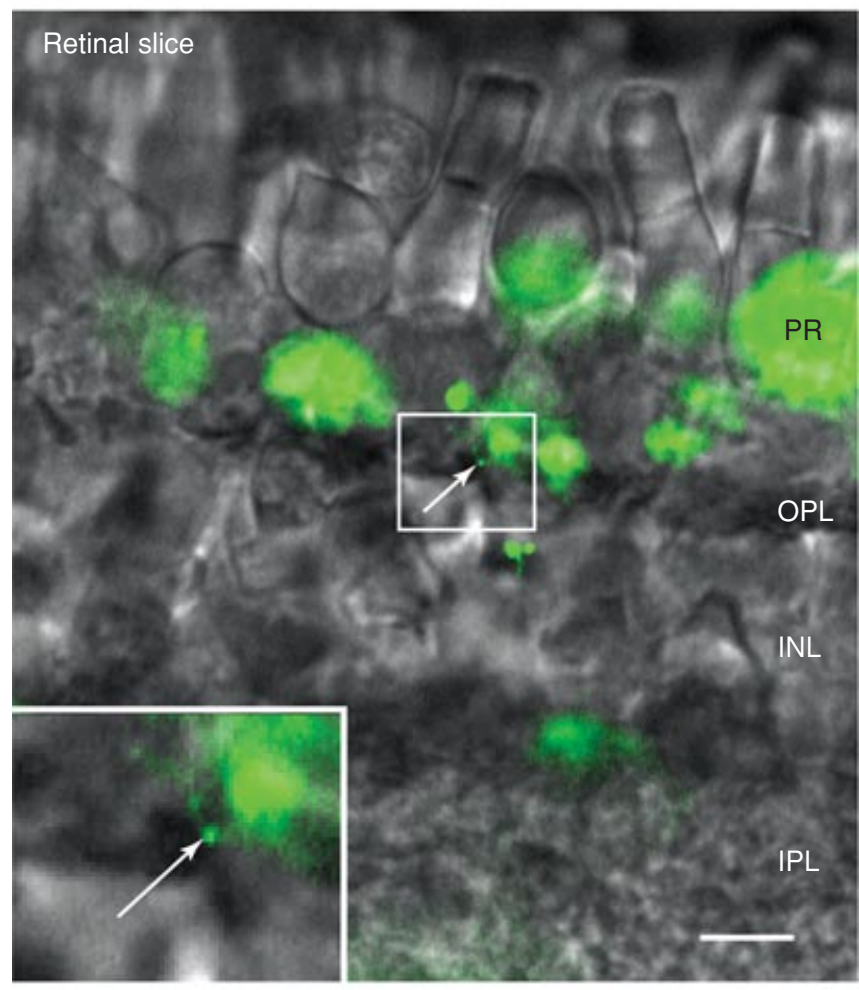

B

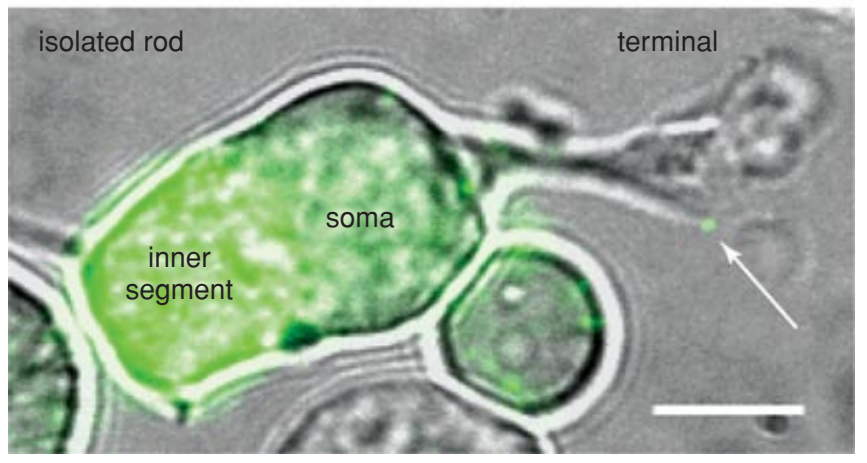

Figure 2.18.2 Images of photoreceptors labeled with QDs. (A) QD attached to the $\alpha_{2} \delta_{4}$ subunit of a cone in the outer plexiform layer (OPL) of an amphibian retinal slice (arrow). The photoreceptor (PR) layer, OPL, inner nuclear layer (INL), and inner plexiform layer (IPL) are labeled in the figure. A higher-powered magnification of the QD is shown in the inset. Retinal slices were prepared as described in Basic Protocol 1. (B) A single QD attached to a $\mathrm{Ca}_{v}$ channel in the synaptic terminal of an isolated rod (arrow). The terminal, soma and inner segment regions are labeled. Cells were enzymatically dissociated as described in Support Protocol 2. In both images, one can see nonspecific autofluorescence in the inner segments due to flavoproteins in the mitochondrialrich ellipsoid region (Kunz and Kunz, 1985). QDs were attached to extracellular Cav channel $\alpha_{2} \delta_{4}$ subunits using the techniques described in Basic Protocol 2. Anatomical location, intermittent blinking, and a small size $<8$ pixels were used to identify QDs for tracking analysis. For this figure, QD fluorescence was averaged from 400 frames acquired at $50-\mathrm{msec}$ intervals in $\mathrm{A}$ and $30-\mathrm{msec}$ intervals in B. Bright-field images were acquired using a 100-msec acquisition period. Fluorescent images were pseudo-colored green and overlaid onto bright-field images using ImageJ. Scale bar $=10 \mu \mathrm{m}$. 


\section{Pre-apply bovine serum albumin to limit nonspecific binding of the secondary antibody}

1. Remove most of the HAESS from the slices in the perfusion chamber but not enough to expose the slices to air. Replace the solution with 200 to $250 \mu$ HAESS containing $1 \%(\mathrm{w} / \mathrm{v}) \mathrm{BSA}$ and place at $4^{\circ} \mathrm{C}$ for $15 \mathrm{~min}$.

BSA is used to prevent nonspecific binding of the secondary antibody. You can also use serum matching the species in which the secondary antibody was generated.

2. Rinse the slices three times with ice-cold HAESS.

\section{Apply antibodies to the retinal preparation}

3. Dilute the anti- $\alpha_{2} \delta_{4}$ primary antibody $1: 1000$ in ice-cold HAESS and apply to the retinal slices. Place the perfusion chamber in a humidified chamber at $4^{\circ} \mathrm{C}$ for $3 \mathrm{hr}$.

Our simple humidified environment consists of a large petri dish with the perfusion chamber in the center and damp paper towels at the periphery.

4. Rinse the slices three times with ice-cold HAESS.

5. Dilute the secondary antibody 1:2000 in ice-cold HAESS. Apply to the retinal slices, and place the perfusion chamber back in the humidified chamber at $4^{\circ} \mathrm{C}$ for $1 \mathrm{hr}$.

6. Rinse the slices three times with ice-cold HAESS.

\section{Attach QDs to antibodies bound to $C a_{V} 1.4 / \alpha_{2} \delta_{4}$ subunits}

7. Dilute the Qdot 525 Streptavidin Conjugate stock to $20 \mathrm{nM}$ in ice-cold HAESS. Apply to the retinal slices and incubate in the dark for $15 \mathrm{~min}$ at room temperature.

8. Rinse the slices five times with ice-cold HAESS. Make sure that sufficient HAESS remains on the slices for subsequent imaging.

Antibody incubation periods are an excellent time to co-apply pharmacological reagents such as cytochalasin $D$ to disrupt the actin cytoskeleton or methyl- $\beta$-cyclodextrin to remove membrane cholesterol (Mercer et al., 2011a, 2012).

BASIC PROTOCOL 3

\section{Tracking Calcium \\ Channel Movements}

\subsection{8}

\section{IMAGING AND ANALYSIS OF INDIVIDUAL QDS ON RETINAL SLICES}

An advantage of QD imaging for SPT is the relative ease with which QDs can be imaged. The primary components required for data acquisition are a microscope with an epifluorescent light source, a high-numerical aperture (high-NA) objective, and an electron-multiplying charged coupled device (EMCCD) camera. We use QDs that fluoresce at approximately the same excitation and emission spectra as the fluorophore FITC and can therefore be imaged with a FITC filter set. The high quantum yield and single-photon sensitivity of EMCCD cameras are important for visualizing single QDs. Image brightness is proportional to $\left(\mathrm{NA}^{4} /\right.$ magnification $\left.^{2}\right)$, and so higher-NA objectives significantly improve signal-to-noise quality (Mavrakis et al., 2008).

NOTE: When not actively imaging QDs, perfuse slices with ice-cold HAESS bubbled with $100 \% \mathrm{O}_{2}$ to maintain health and integrity of retinal tissue. However, briefly stop perfusion during imaging to prevent any effects of fluid flow on QD movements.

\section{Materials}

Antibody-incubated retinal tissue (Basic Protocol 2)

TMC vibration isolation table

Nikon E600FN upright microscope with the following components:

$60 \times, 1.2-$ or 1.0-NA water-immersion objective

FITC filter cube (Chroma Technologies, cat. no. 41001)

$\mathrm{Hg} / \mathrm{Xe}$ epifluorescent light source (OptiQuip, http://optiquipsurgical.com/) 
Lambda 10-2 shutter (Sutter Instruments)

Photometrics Ds-Qi1 EMCCD camera

Nikon NIS-Elements Imaging Software

Computer running Microsoft Excel

NOTE: The specific components of a single imaging setup vary among laboratories. We describe the setup used for our studies in retinal slices as a foundation for others to follow.

1. Identify the retinal outer plexiform layer (OPL).

The synapses of rod and cone photoreceptors terminate on dendrites of bipolar and horizontal cells in the OPL of the retina. The OPL is visible in bright-field microscopy as a thin layer separating the photoreceptor cell bodies from the cell bodies of bipolar and horizontal cells residing in the inner nuclear layer (INL) (Fig. 2.18.2A).

\section{Identify and image synaptic terminals with attached QDs}

2. Switch to epifluorescent imaging, and pan slowly through a retinal slice to identify single QDs.

Single QDs can be easily visualized by increasing the electron multiplier function of the EMCCD camera to enhance the fluorescent signal.

This may require some patience, as our dilutions only label a few dozen channels in an entire retina preparation. QDs more often bind to tissue at the surface of the cut slice. Whenever possible, we choose channels embedded more deeply in the slice under the assumption that this tissue is likely to be healthier and more intact.

$Q D$ s blink occasionally, and this property can help to ensure that you are imaging a single $Q D$.

In NIS-Elements Software, one can optimize the Look-Up Table (LUT) function to maximize gain versus background to improve visualization of a single $Q D$.

3. Set the parameters for imaging in your software.

With 1.0- to 1.2-NA, $60 \times$ objectives, we typically acquire 400 images at 50 msec/image. With a 1.45-NA objective used for imaging cells on an inverted microscope, the brighter fluorescence allows us to acquire images at 15 to 30 msec/image.

4. Open the shutter and acquire a $20-\sec (20-\mathrm{Hz})$ video.

You may wish to repeat this a few times. Signal-to-noise often improves with longer epifluorescent illumination, as tissue autofluorescence tends to bleach with continued exposure whereas $Q D$ fluorescence does not.

QD signal optimization and SPT analysis: Mean squared displacement, diffusion coefficient, and confinement area

5. For post-image analysis, use the auto-LUT feature of NIS-Elements to maximize signal and minimize background.

6. Enhance QD intensity further by filtering the image with a $5 \times 5$-pixel Gaussian convolution function.

7. Crop the image to a small region surrounding the QD of interest.

Tightly cropping the image limits artifactual jumps to other nearby fluorescent objects.

8. Use the tracking software to track the position of the QD.

Your readout should include (at minimum) the frame number, time (in msec), and the distance readout ( $X$ and $Y$ coordinates in $\mu \mathrm{m}$ ). Figure 2.18.3A shows a map of the positions occupied by a QD-labeled Ca $a_{V}$ channel at 30-msec intervals for 15 sec. For comparison, the right side of Fig. 2.18.3A shows a trajectory map for a QD immobilized in vacuum grease on the surface of the glass.

Camera resolution ( $\mu \mathrm{m} /$ pixel) should be determined with a calibration slide. 
A trajectory map
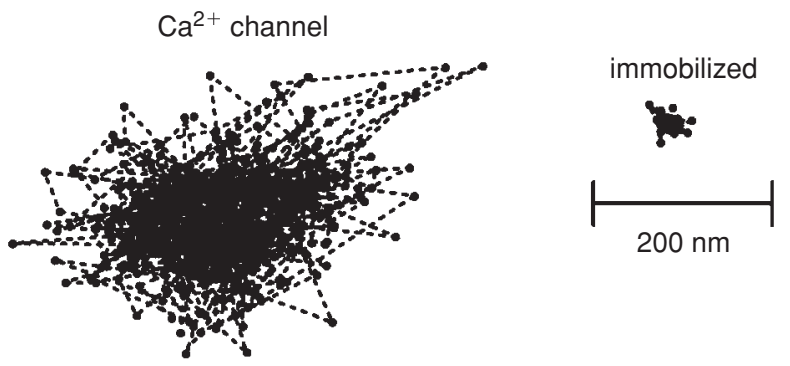

B mean squared displacement

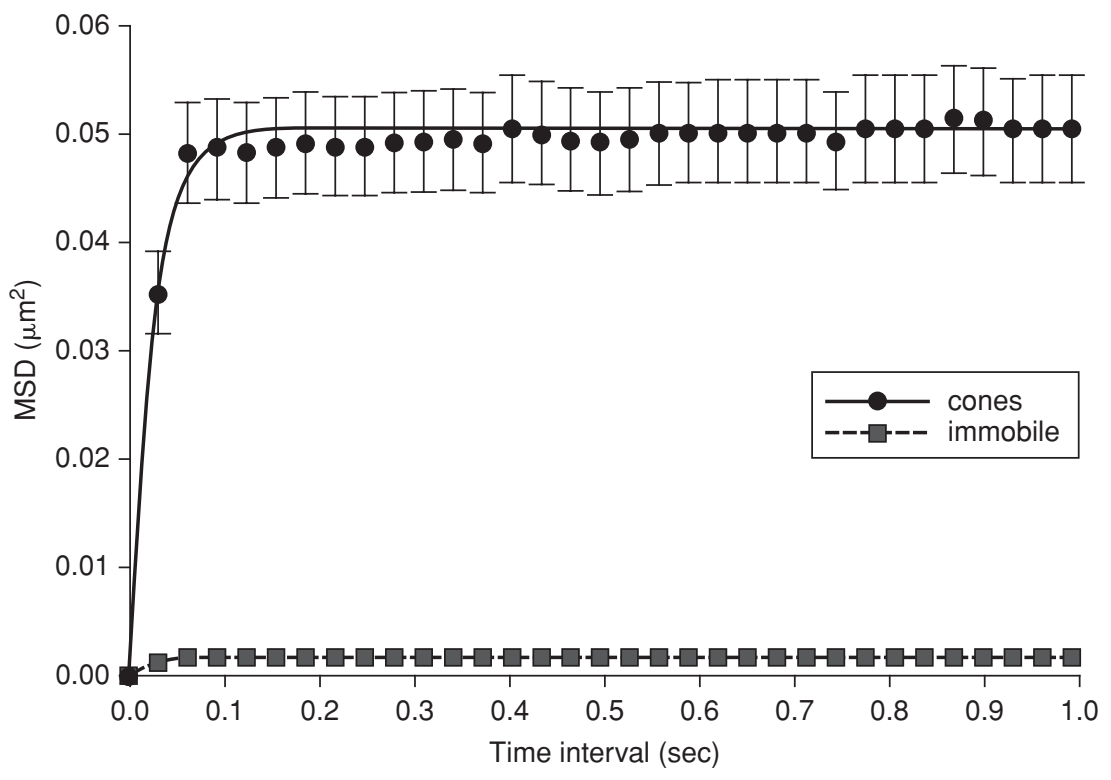

Figure 2.18.3 QD trajectory plot and MSD analysis. (A) Representative trajectory map of a QD attached to $\mathrm{a} \mathrm{Ca}_{v}$ channel on the terminal of an isolated cone photoreceptor. Individual trajectory points show the coordinates of a single QD every $30 \mathrm{msec}$ during a 12-sec acquisition period. Immobilized QDs, such as that shown at the right, exhibit trajectory maps that are a fraction of those exhibited by QDs moving at photoreceptor synapses. QD-attached $\mathrm{Ca}_{v}$ channels at the synapses of isolated cone photoreceptors were imaged following Basic Protocol 3. Photoreceptors were imaged using an Olympus IX71 inverted microscope and a 1.45-NA oil-immersion objective. (B) Raw $x$ and y data from QD SPT experiments were analyzed using the equations described in step 9a of Basic Protocol 3. Mean squared displacement (MSD) data are plotted as a function of the measurement time interval. QD-labeled Cav channels (black circles) show a significantly greater increase in MSD than immobilized QDs (squares). The MSD of cone Cav channels quickly reached a plateau, indicating that these proteins are confined within a limited domain. To calculate the size of the confinement domain, we fit the data with the equation in step 9c of Basic Protocol 3. In this sample, we found that cone $\mathrm{Ca}_{v}$ channels were confined to a surface area of $0.15 \mu \mathrm{m}^{2}$, consistent with previous observations in retinal slice and dissociated retina preparations (Mercer et al., 2011a; Mercer et al., 2012).

\section{Perform SPT analysis in Microsoft Excel.}

The most basic analysis involves determining the mean squared displacement (spread of particle position) as a function of measurement time interval. Figure 2.18.3B shows a plot of mean squared displacement versus acquisition time interval for $Q D$ s imaged at the terminals of isolated cones using a $60 \times, 1.45$-NA objective (circles). The negligible mean squared displacement for immobilized QDs is also illustrated (squares). From these data, one can calculate the diffusion coefficient (rate of diffusion in the plasma membrane) and confinement area (surface area that confined proteins move within).

2.18.10 
a. Mean squared displacement (MSD):

$$
\operatorname{MSD}=\frac{1}{N-n} \sum_{i=1}^{N-n}\left(\left[X_{i+n}-X_{i}\right]^{2}+\left[Y_{i+n}-Y_{i}\right]^{2}\right)
$$

In this equation, $N$ denotes the frame number, $n$ denotes the starting frame number, $X$ denotes the position on the $X$ axis (in $\mu \mathrm{m}$ ), $Y$ denotes the position on the $Y$ axis (in $\mu \mathrm{m}$ ), and $i$ denotes the first frame of an image series.

b. Diffusion coefficient:

$$
\mathrm{MSD}=4 D \Delta t
$$

The diffusion coefficient $(D)$ is calculated from the slope of the increase in MSD versus time interval. For free diffusion, the MSD increases linearly with increasing time intervals. For confined diffusion, the MSD levels off onto a plateau. The MSD for photoreceptor $\mathrm{Ca}_{V}$ channels rises linearly with time intervals up to $\sim 50 \mathrm{msec}$, after which the MSD begins to plateau indicating confinement. The slope of the line fit to data points during the first 50 msec before the MSD reaches a plateau can be used to determine $D$, in $\mu \mathrm{m} / \mathrm{sec}$.

c. Confinement domain:

$$
\operatorname{MSD}=\frac{L^{2}}{3}\left(1-\exp \frac{-12 D \Delta t}{L^{2}}\right)
$$

The presence of a plateau in the MSD versus time interval plot indicates that a particle is confined within in a limited domain (Saxton and Jacobson, 1997). The surface area of this confinement domain $\left(L^{2}\right)$ can be determined from the above equation.

\section{CONSTRUCTION OF THE RETINAL SLICE PERFUSION CHAMBER}

The main body of each perfusion chamber is constructed from acrylic plastic, which can be purchased from a variety of sources. The dimensions described in this support protocol are optimized for preparation of the retinal slice model in Basic Protocol 1. The perfusion chamber can be constructed using standard machine shop tools. Further details and diagrams of the chamber are available elsewhere (Van Hook and Thoreson, 2012).

\section{Materials}

Machine shop tools

2 mm-thick acrylic plastic

20-G plastic tubing

$\mathrm{Ag} / \mathrm{AgCl}$ reference electrode

Reference lead wire

$25 \times 75-\mathrm{mm}$ glass slide

Spinal needles, 20-GA, 3.5-in. (BD Medical Systems)

Small screws

1. Cut a $35 \times 100-\mathrm{mm}$ rectangle of acrylic plastic ( $2 \mathrm{~mm}$ thick).

2. Cut a $21 \times 71-\mathrm{mm}$ rectangular hole in the center of this piece of plastic.

3. Cut a shallow inset along the inner edge of plastic bordering the rectangle in the center of the chamber; this inset should extend $2 \mathrm{~mm}$ into the plastic chamber and be $1 \mathrm{~mm}$ thick.

This inset allows for attachment of a glass slide with vacuum grease to the base of the chamber. 
SUPPORT PROTOCOL 2

Tracking Calcium Channel Movements

\subsubsection{2}

4. At the center of both long sides of the chamber, drill holes parallel to the base of the chamber. In one of these holes, insert a $10-\mathrm{cm}$ length of $20-\mathrm{G}$ plastic tubing to use as an inflow port for HAESS during recordings; the other hole can be used to insert an $\mathrm{Ag} / \mathrm{AgCl}$ pellet reference electrode into the chamber.

If you need an $\mathrm{Ag} / \mathrm{AgCl}$ reference electrode for electrophysiology, drill two nearby holes ( $\sim 2$ to $3 \mathrm{~mm}$ in diameter) through the chamber from the upper surface and insert small screws to anchor the lead wire.

5. On the short side of the chamber adjacent to the reference electrode, drill a hole parallel to the base of the chamber for a 20-GA spinal needle. Insert a 20-GA spinal needle.

You may wish to use emery paper or a whetstone to dull the tip and expand the opening of the beveled ending.

By connecting this tube to a vacuum supply, one can apply suction to remove superfusate after it has flowed over the retina.

A $25 \mathrm{~mm} \times 75-\mathrm{mm}$ glass slide can be attached into the bottom of the recording chamber, and retinal tissue can be prepared in the chamber as described in Basic Protocol 1.

\section{DISSOCIATED AMBYSTOMA TIGRINUM RETINAL PREPARATION}

As a comparison to retinal slices, we regularly employ a dissociated retinal cell preparation to study solitary rods and cones (Thoreson et al., 1997; Krizaj et al., 2011; Mercer et al., 2012). This protocol outlines how to isolate and dissociate living retinal tissue for imaging and electrophysiological analysis.

\section{Materials}

Concanavalin A (Sigma-Aldrich, cat. no. C7275) or CellTak (BD Biosciences)

Sylgard (optional)

$0.5 \mathrm{mM} \mathrm{Ca}^{2+}$ HAESS (low $\mathrm{Ca}^{2+}$ version of HAESS; see recipe)

Bovine serum albumin (BSA; Sigma-Aldrich, cat. no. A9418)

Cysteine (Sigma-Aldrich, cat. no. 168149)

Papain (Sigma-Aldrich, cat. no. 76220)

DNase (Worthington Biochemicals, cat. no. LS0066331)

18-mm-diameter glass coverslips

Imaging chamber for 18-mm coverslips (Warner Instruments, cat. no. RC-41LP)

35-mm petri dishes

Rocking platform

Pasteur pipet with a fire-polished tip, $\sim 1 \mathrm{~mm}$ O.D., and attached rubber bulb

Pasteur pipet with large $(\sim 5 \mathrm{~mm})$ fire-polished opening to use as a transfer pipet

Additional reagents and equipment for isolation, enucleation, and quartering of salamander eyecup (Basic Protocol 1, steps 4 to 19)

\section{Prepare the perfusion chamber}

1. Coat the center of an 18-mm glass coverslip with $\sim 200 \mu \mathrm{l}$ concanavalin A $(1 \mathrm{mg} / \mathrm{ml}$ in deionized water) and allow to dry. Alternatively, coat the coverslip with Cell Tak $\left(3.5 \mu \mathrm{g} / \mathrm{cm}^{2}\right.$ for $\left.\sim 30 \mathrm{~min}\right)$.

2. Mount the coated coverslip into the imaging chamber (or use a coverslip mounted by Sylgard over a hole in the bottom of a $35-\mathrm{mm}$ tissue culture dish).

\section{Prepare solutions}

$0.5 \mathrm{mM} \mathrm{Ca}^{2+}$ HAESS and $0.5 \mathrm{mM} \mathrm{Ca}^{2+}$ HAESS with $1 \%$ BSA can be made prior to the experiment and stored at $-20^{\circ} \mathrm{C}$. Solutions containing cysteine, papain, and DNase must be prepared fresh before each experiment. 
3. Add $0.2 \mathrm{mg} / \mathrm{ml}$ cysteine to $0.5 \mathrm{mM} \mathrm{Ca}^{2+}$ HAESS.

4. Add $\sim 30 \mathrm{U}$ of papain to $1 \mathrm{ml}$ of $0.5 \mathrm{mM} \mathrm{Ca}^{2+}$ HAESS with $0.2 \mathrm{mg} / \mathrm{ml}$ cysteine.

The solution will initially be cloudy until cysteine activates the papain enzyme.

5. Add $5 \mathrm{mg}$ of DNase to $0.5 \mathrm{mM} \mathrm{Ca}^{2+}$ HAESS with $1 \% \mathrm{BSA}$ ( $5 \mathrm{ml}$ total).

\section{Isolate and enzymatically dissociate the retinal tissue}

6. Follow steps 4 to 19 of Basic Protocol 1 to isolate, enucleate, and quarter a salamander eyecup. Use $0.5 \mathrm{mM} \mathrm{Ca}^{2+}$ HAESS for the entire surgical and isolation procedure.

7. Using a large-bore transfer pipet, transfer the translucent retinal tissue into a microcentrifuge tube containing the cysteine/papain digestion solution.

8. Place the microcentrifuge tube on a rocking platform and incubate at room temperature for $25 \mathrm{~min}$.

9. Using a fire-polished Pasteur pipet with $\sim 5 \mathrm{~mm}$-wide tip, transfer the retinal tissue to a petri dish containing $5 \mathrm{ml}$ of ice-cold $0.5 \mathrm{mM} \mathrm{Ca}^{2+}$ HAESS with $1 \%$ BSA and $1 \mathrm{mg} / \mathrm{ml}$ DNase. Allow this tissue to rest for $3 \mathrm{~min}$.

The presence of BSA helps to neutralize further digestion by papain. The DNase makes the tissue less sticky by digesting DNA released from damaged cells.

10. Using the large-bore transfer pipet, transfer the tissue to a petri dish containing $5 \mathrm{ml}$ of ice-cold $0.5 \mathrm{mM} \mathrm{Ca}^{2+}$ HAESS and allow to incubate at room temperature for 3 min.

11. Repeat step 10.

\section{Mechanically dissociate the retinal tissue and plate cells}

12. Aspirate the retinal tissue along with $\sim 1 \mathrm{ml} 0.5 \mathrm{mM} \mathrm{Ca}^{2+}$ HAESS into a firepolished Pasteur pipet with $\sim 1 \mathrm{~mm}$ diameter opening at the tip. Transfer to a 1-ml microcentrifuge tube. Triturate the cells by smoothly drawing the tissue and solution up and down through the tip of the pipet until the retina begins to fray. Avoid bubbles and excessive turbulence.

13. Aspirate $\sim 500 \mu \mathrm{l}$ of the cell suspension onto the coated coverslip, leaving larger retinal pieces in the microcentrifuge tube.

14. Further triturate the remaining pieces of tissue in $\sim 500 \mu \mathrm{l}$ of solution and then plate additional cells onto the coverslip.

15. Let cells settle and adhere for 20 to $30 \mathrm{~min}$ at $4^{\circ} \mathrm{C}$.

16. Proceed to Basic Protocol 2 to label dissociated retinal neurons with antibodies and QDs.

\section{CONTROLS}

\section{Materials}

HEPES-buffered extracellular amphibian saline solution (HAESS; see recipe)

Agar

Quantum dots (QDs; Invitrogen, cat. no. Q10141MP; $1 \mu \mathrm{M}$ solution)

Dow Corning vacuum grease

Plastic perfusion chamber (Support Protocol 1)

Additional reagents and equipment for antibody-based QD attachment (Basic Protocol 2) to fixed retinal tissue (Support Protocol 4) 
1. Prepare and image immobilized QDs.

Immobilized QDs can be used to determine baseline measurement noise and pointing accuracy for tracking of $Q D$ locations. The pointing accuracy can be determined from the standard deviation of positions for an immobilized $Q D$. In a noise-free system, the maximum possible resolution would match the core diameter of the $Q D(<10 \mathrm{~nm})$. The resolution (full width half maximum $=2.355 \times$ s.d.) that we obtained with a 1.45-NA, $60 \times$ objective ( $30 \mathrm{msec}$ acquisition time) was $\sim 35 \mathrm{~nm}$; with a 1.2-NA, $60 \times$ objective ( $50 \mathrm{msec}$ ) was $\sim 55 \mathrm{~nm}$; and with a 1.0-NA, $60 \times$ objective (50 msec) was $\sim 115 \mathrm{~nm}$. Resolution tends to decrease with use of shorter acquisition times or lower-NA objectives as QD brightness diminishes. We have used three techniques to immobilize $Q D$, as described in the substeps below.

a. Use the antibody-based QD targeting strategy (Basic Protocol 2) to attach QDs to fixed retinal tissue (Support Protocol 4). Apply enough HAESS to cover the tissue and image as outlined above.

b. Prepare a solution of $2 \%(20 \mathrm{nM})$ agar in deionized water and "spike" the solution with 2\% (20 nM) QDs. Spread this solution onto a perfusion chamber and allow the agar to solidify. Apply HAESS on top of the agar/QD paste and image as described above.

c. Smear a thin layer of vacuum grease in the center of a perfusion chamber. Apply $200 \mu \mathrm{l}$ of $20 \mathrm{nM}$ QDs. Allow the QDs to rest for $10 \mathrm{~min}$, and then wash eight times.

$Q D$ s bound in the vacuum grease can be imaged as an immobilized $Q D$ control (Fig. 2.18.3A, right).

Heat from the camera or other sources can cause the vacuum grease to become more fluid and QDs to become mobile.

2. Validate the antigenic specificity of the anti- $\alpha_{2} \delta_{4}$ antibody.

We used two different techniques to validate the antigenic specificity of the anti- $\alpha_{2} \delta_{4}$ antibody as described below.

a. Elimination of either the primary anti- $\alpha_{2} \delta_{4}$ antibody or the secondary biotinylated anti-rabbit goat antibody. Removal of either antibody should remove a specific target for the streptavidin-coated QDs.

b. Pre-incubation of the anti- $\alpha_{2} \delta_{4}$ antibody with the antigenic peptide (AcKVSDRKFLTPEDEASVC-amide).

The anti- $\alpha_{2} \delta_{4}$ antibody was developed against this specific epitope of the $C a_{V}$ channel $\alpha_{2} \delta_{4}$ subunit (Qin et al., 2002), and thus preincubation with this peptide should occupy the $F_{a b}$ arms of the anti- $\alpha_{2} \delta_{4}$ antibody and prevent the anti- $\alpha_{2} \delta_{4}$ antibody from binding the anti- $\alpha_{2} \delta_{4}$ subunit on $C a_{V} 1.4$ channels in the retinal tissue.

SUPPORT PROTOCOL 4

\section{Tracking Calcium Channel Movements}

\subsubsection{4}

\section{FIXED TISSUE IMMUNOHISTOCHEMISTRY OF AMBYSTOMA TIGRINUM EYES}

Fixed retinal tissue can be used to validate the baseline optical properties of immobilized QDs (Support Protocol 3, step 1) or to confirm the anatomical specificity of reagents used in QD-based antibody targeting. In this protocol, we explain how to prepare Ambystoma tigrinum eyecups for histological sectioning and antibody staining.

\section{Materials}

$4 \%$ paraformaldehyde (see recipe)

$30 \%(\mathrm{w} / \mathrm{v})$ sucrose in deionized $\mathrm{H}_{2} \mathrm{O}$

0.1 M phosphate-buffered saline, pH 7.4 (PBS; APPENDIX 2A)

OCT Compound (Sakura FineTek, cat. no. 4853) 
Pulverized dry ice

Blocking solution (see recipe)

Normal serum

Primary antibody: rabbit anti- $\alpha_{2} \delta_{4}$ antibody (Qin et al., 2002)

Secondary antibody: goat anti-rabbit fluorophore-conjugated secondary antibody

(e.g., FITC-conjugated anti-rabbit IgG; Sigma-Aldrich, cat. no. F0382)

VectaShield Hard Mount with DAPI (Vector Labs, cat. no. H-1200)

Tissue-Tek cryomolds $(10 \mathrm{~mm} \times 10 \mathrm{~mm} \times 5 \mathrm{~mm})$

Leica CM1800 cryostat

Fisher SuperFrost glass slides

PAP pen (or colored nail polish)

Humidified chamber: large petri dish with the slide containing the section placed at the center and damp paper towels at the periphery

Razor blades

$24 \mathrm{~mm} \times 60 \mathrm{~mm}$ coverslips

Additional reagents and equipment for removing the eyes from a tiger salamander

(Basic Protocol 1, steps 4 to 13) and cryostat sectioning (UNIT 1.1)

\section{Tissue fixation}

1. Remove the eyes from a tiger salamander by following steps 4 to 13 of Basic Protocol 1.

2. Place the intact eye into a solution of $4 \%$ paraformaldehyde for $4 \mathrm{hr}$ at $4{ }^{\circ} \mathrm{C}$.

3. Cryoprotect the eye by placing it in $30 \%$ sucrose (w/v) overnight at $4{ }^{\circ} \mathrm{C}$.

4. Rinse the eye briefly in $0.1 \mathrm{M}$ PBS to remove excess sucrose.

\section{Tissue sectioning}

5. Place the eye into a cryomold with the anterior portion of the eye facing laterally. Carefully cover the eye with OCT compound.

6. Submerge the cryomold in pulverized dry ice to flash-freeze the eye tissue.

7. Slice the OCT/eye block into 25- to $30-\mu \mathrm{m}$ sections using the cryostat (see UNIT 1.1). Mount slices onto glass slides slice-by-slice.

Some laboratories use gelatin-coated glass slides; this is up to the user's discretion.

Ambystoma tigrinum retinal neurons are larger than many neurons in mammalian retinas. The width of a rod or cone in the tiger salamander retina averages $\sim 12 \mu \mathrm{m}$, and so sections should be cut at least twice this thickness to maintain the cellular layers for histological analysis.

8. Thaw frozen sections in a tissue culture incubator at $37^{\circ} \mathrm{C}$ for $10 \mathrm{~min}$.

\section{Histology}

9. Make temporary wells around individual eye sections using a PAP pen or colored nail polish. Allow the PAP pen or nail polish to dry completely.

10. Wash sections three times with $0.1 \mathrm{M}$ PBS, immersing the slide for $10 \mathrm{~min}$ per wash.

11. Block nonspecific binding on sections by incubating them in blocking solution for 1 $\mathrm{hr}$ at room temperature.

12. Wash sections three times with $0.1 \mathrm{M}$ PBS, immersing the slide for $10 \mathrm{~min}$ per wash. 
13. Dilute the rabbit anti- $\alpha_{2} \delta_{4}$ primary antibody $1: 1000$ in 0.1 M PBS with $10 \%$ normal serum. Incubate overnight at $4^{\circ} \mathrm{C}$ in a humidified chamber.

14. Wash sections $3 \times$ with $0.1 \mathrm{M}$ PBS, 10 min per wash.

15. Dilute the goat anti-rabbit fluorophore-conjugated secondary antibody 1:2000 in 0.1 M PBS. Apply to the section for $1 \mathrm{hr}$ at room temperature in a humidified chamber in the dark.

16. Wash sections three times with $0.1 \mathrm{M}$ PBS, immersing the slide for $10 \mathrm{~min}$ per wash.

17. Allow sections to dry completely. Briefly rinse with deionized water and allow sections to dry.

18. Use a razor blade to carefully scrape off the PAP pen or nail polish from the slide.

19. Apply $\sim 150$ to $250 \mu \mathrm{l}$ VectaShield mounting medium and apply a coverslip to the sections immediately.

20. Allow mounted slides to dry overnight before imaging.

\section{REAGENTS AND SOLUTIONS}

Use deionized, distilled water in all recipes and protocol steps. For common stock solutions, see APPENDIX 2A; for suppliers, see SUPPLIERS APPENDIX.

\section{Blocking solution}

0.1 M phosphate-buffered saline (PBS; APPENDIX 2A) containing:

$10 \%(\mathrm{v} / \mathrm{v})$ normal serum

$1 \%(\mathrm{w} / \mathrm{v})$ bovine serum albumin (BSA; Sigma-Aldrich, cat. no. A9418)

$0.5 \%(\mathrm{v} / \mathrm{v})$ Triton X-100

Store up to 1 week at $4{ }^{\circ} \mathrm{C}$

Serum should be from the species of secondary antibody used to visualize the location of primary antibodies. Endogenous antibodies present in the serum should bind nonspecific epitopes that the secondary antibody might otherwise detect.

\section{HEPES-buffered extracellular amphibian saline solution (HAESS)}

$111 \mathrm{mM} \mathrm{NaCl}$

$2.5 \mathrm{mM} \mathrm{KCl}$

$1.8 \mathrm{mM} \mathrm{CaCl}_{2}\left(0.5 \mathrm{mM} \mathrm{CaCl}_{2}\right.$ for the dissociated retinal preparation $)$

$0.5 \mathrm{mM} \mathrm{MgCl}_{2}$

$10 \mathrm{mM}$ HEPES

$5 \mathrm{mM}$ glucose (add just before use; solution should be used within $72 \mathrm{hr}$ of adding glucose)

Store buffer with the above ingredients up to 1 month at $4^{\circ} \mathrm{C}$

Osmolarity values for HAESS should be $\sim 240$ to $245 \mathrm{mOsm}$ and can be adjusted if necessary with water or glucose.

\section{4\% paraformaldehyde}

For 1-liter of $4 \%$ paraformaldehyde, dissolve $40 \mathrm{~g}$ paraformaldehyde powder (Sigma-Aldrich, cat. no. P6148) in $500 \mathrm{ml}$ of water. Add one to three $\mathrm{NaOH}$ pellets to the solution and stir on a hot plate $\left(60^{\circ} \mathrm{C}\right.$; do not overheat). After the paraformaldehyde has dissolved and the solution is relatively clear, add $154.8 \mathrm{ml}$ of $1 \mathrm{M} \mathrm{Na}_{2} \mathrm{HPO}_{4}$ and $45.2 \mathrm{ml}$ of $1 \mathrm{M} \mathrm{NaH}_{2} \mathrm{PO}_{4}$ (resulting in a $0.2 \mathrm{M}$ phosphate buffer). Make the solution up to a 1 liter volume using a volumetric flask. The final $\mathrm{pH}$ of this solution should be $\sim 7.4$. Filter the paraformaldehyde solution and chill at $4{ }^{\circ} \mathrm{C}$. Prepare fresh immediately before use. 


\section{Background Information}

Neuron-to-neuron communication begins with the opening of $\mathrm{Ca}_{\mathrm{V}}$ channels at a presynaptic axon terminal by a depolarizing stimulus. The influx of $\mathrm{Ca}^{2+}$ triggers fusion proteins in the presynaptic membrane to intertwine with surface proteins on synaptic vesicles, inducing the fusion of vesicles with the presynaptic plasma membrane (Neher and Sakaba, 2008). $\mathrm{Ca}_{\mathrm{V}}$ channels are positioned close to release sites at the presynaptic active zone of many fast synapses, ensuring precise and efficient release (Eggermann et al., 2012). The clustering of $\mathrm{Ca}_{\mathrm{V}}$ channels at the presynaptic active zone involves interactions between $\mathrm{Ca}_{\mathrm{V}}$ channels and a variety of different synaptic proteins including Rim, CAST/ELKS, and bassoon (Mercer and Thoreson, 2011). Despite these many interacting protein partners, $\mathrm{Ca}_{\mathrm{v}}$ channels are nevertheless capable of moving in the membrane (Mercer et al., 2011a). This is similar to the movements of transmembrane receptors and channels in the postsynaptic membrane (Dahan et al., 2003; Charrier et al., 2006; Groc et al., 2008; Mikasova et al., 2008; Bannai et al., 2009). Channel movements can have important functional consequences. For example, movements of undesensitized AMPA receptors into the synapse can facilitate recovery from synaptic depression (Heine et al., 2008). Physiological activity can regulate interactions between ion channels and the cytoskeleton (Choquet, 2010; Liu et al., 2011) as well as the movements of ion channels (Gomez-Varela et al., 2010; Mercer et al., 2011a). Synaptic activity has also been shown to promote transient interactions that briefly immobilize the presynaptic SNARE protein syntaxin (Ribrault et al., 2011). Changes in channel mobility can also regulate physiological activity. For example, by allowing $\mathrm{Ca}_{\mathrm{V}}$ channels to move further away from release sites, depletion of membrane cholesterol reduces release efficiency so that a greater number of channel openings are needed to trigger release of a synaptic vesicle (Mercer et al., 2012).

There are a number of obstacles to examining the movements of membrane proteins. First, the ability to visualize small structures by conventional fluorescent imaging methods is limited by the resolution of the microscope. With a typical fluorescence microscope, the resolution is limited by the diffraction limit of light ( $300 \mathrm{~nm}$ ), which is significantly larger than the size of many membrane proteins
(Alcor et al., 2009). Second, the maximum signal intensity of many synthetic or transgenic fluorescent probes is lost within a few seconds of imaging due to photobleaching (Chan and Nie, 1998; Smith et al., 2008). A reduction in the emission of a fluorophore can limit data acquisition, and even render some lengthy experiments impossible. Finally, a camera capable of imaging small fluorophores accurately on a very short time scale is necessary to observe the natural motion of synaptic proteins.

The development of quantum dots (QDs) as semiconductor molecules (Takagahara, 1987; Reed et al., 1988) was rapidly extended to biological applications, as it was discovered that QDs luminesce ten-fold brighter and are over a hundred times more photostable than traditional organic dyes such as fluorescein isothiocyanate (FITC) and rhodamine (Bruchez et al., 1998; Chan and Nie, 1998; Jares-Erijman and Jovin, 2003). These optical properties allow for the direct imaging of QDs for minutes to hours. Furthermore, the bright centroid of a QD can be localized by fitting the fluorescent signal with a Gaussian convolution with a pointing accuracy that far exceeds the diffraction limit of standard fluorescent microscopy (Saxton, 1997; Bannai et al., 2006). Furthermore, QDs were eventually developed into water-soluble compounds that could be coupled with an array of possible bioconjugates. This allowed for the development of in vitro and in vivo QD applications, notably in the areas of optical imaging and diagnostics (Medintz et al., 2005; Probst et al., 2012). Together, these properties have made QDs an important molecular imaging tool. The adaptability, photostability, and nanometer-scale accuracy of QD location offer a tool to readily examine cellular components in real-time, such as the mobility of synaptic membrane proteins in living tissue.

At the synapses of vertebrate photoreceptors, release of glutamatergic vesicles is controlled by $\mathrm{Ca}^{2+}$ influx through L-type $\mathrm{Ca}_{\mathrm{V}}$ channels (Thoreson, 2007). The location and function of $\mathrm{Ca}_{\mathrm{V}}$ channels had been determined using anatomical and electrophysiological techniques (Raviola and Gilula, 1975; Nachman-Clewner et al., 1999; tom Dieck et al., 2005; Mercer et al., 2011b), but the behavior of these channels in the membranes of living retinal tissue remained unknown. To directly examine the lateral mobility of $\mathrm{Ca}_{\mathrm{V}}$ channels at photoreceptor terminals, we developed a method to attach streptavidin-coated
Imaging

2.18.17

Supplement 62 
QDs to the extracellular $\alpha_{2} \delta_{4}$ accessory subunit of L-type $\mathrm{Ca}_{\mathrm{V}} 1.4$ channels present at photoreceptor synapses (Mercer et al., 2011a, 2012). The results showed that $\mathrm{Ca}_{\mathrm{V}}$ channels are mobile but remain confined within a small area of the presynaptic membrane that matches the size of the ribbon-style active zone revealed from ultrastructure (Raviola and Gilula, 1975; Townes-Anderson et al., 1985; Pang et al., 2008). Fusion of nearby synaptic vesicles alters channel mobility (Mercer et al., 2011a) and, conversely, changes in channel mobility influence vesicle release efficiency (Mercer et al., 2012). Movements of QD-tagged $\mathrm{Ca}_{\mathrm{V}}$ channels can be measured to explore the behavior of individual channels and to map dynamic changes in the size of the active zone membrane. The accessibility of the photoreceptors and the hardiness of this retina preparation make the amphibian retinal slice a valuable model for studying the lateral mobility of single synaptic $\mathrm{Ca}_{\mathrm{V}}$ channels.

\section{Critical Parameters and Troubleshooting}

Age of reagents. It is critical to use fresh reagents. Old HAESS, buffers, enzymes, antibodies, and QD stocks can diminish the success of a QD-based SPT experiment by complicating reagent binding or compromising the health of the retinal preparation. All liquid reagents that we use are stored at $4{ }^{\circ} \mathrm{C}$. Most have a limited shelf life and are only used for up to 2 weeks. In our laboratory, antibodies and serum are pre-aliquotted in microliter quantities and stored at $-80^{\circ} \mathrm{C}$ prior to use. Additionally, we use QDs from Invitrogen for no longer than 4 to 6 months. In our hands, QDs in stock solutions older than 6 months tend to cluster, making SPT imaging quite difficult.

Selection of an appropriate model for study. The protocol we use for our SPT studies requires $4 \mathrm{hr}$ to label a sparse number of single $\mathrm{Ca}_{\mathrm{V}}$ channels. To our benefit, the hardy salamander retina tissue can survive for hours in a HEPES-buffered solution at $4^{\circ} \mathrm{C}$. Not every tissue has these properties, and many may not survive such a lengthy labeling time. For example, mouse retinal slices require a bicarbonate-bubbled extracellular solution with different temperature constraints and a shorter life span for live-cell experiments (Babai and Thoreson, 2009; Babai et al., 2010). In theory, tissue cultures can be labeled with QDs in an incubator, and other ex vivo tissue preparations could be maintained with circulating mini-pumps. We have not yet extended our QD labeling technique to other tissue cultures or organ systems to explore alternative targeting strategies.

Antibody and QD dilutions. Appropriate dilutions for successful QD labeling and SPT are antibody- and tissue-dependent. Therefore, final dilutions should be determined empirically. In Table 2.18.1, we outline common pitfalls during QD labeling and potential solutions to overcome such quandaries.

Selection of QDs for imaging and analysis. To identify QDs for analysis, first use bright-field microscopy to identify the OPL, which is the layer in which both rod and cone photoreceptor axons terminate (Fig. 2.18.2A). For dissociated cells, identify the terminals of healthy-looking rods (Fig. 2.18.2B) or cones. Next, use epifluorescent imaging to identify any attached QDs. Criteria for determining if QDs are adequate for imaging include: (1) QDs localized to the OPL or terminals of isolated photoreceptors consistent with the anatomical location of $\mathrm{Ca}_{\mathrm{V}}$ channels at photoreceptor terminals (Steele et al., 2005; tom Dieck et al., 2005), (2) QDs that do not exhibit rapid Brownian diffusion (i.e., free diffusion in solution) consistent with attachment of QDs to tissue, and (3) QDs with a small size $(<8$ pixels) that exhibit intermittent blinking consistent with labeling by a single QD (Alcor et al., 2009).

Considerations for the dissociated retina preparation. A dissociated retina preparation allows easy access to individual retinal neurons and use of an inverted microscope with high-NA, oil-immersion objectives. Although the preparation of dissociated neurons is less technically demanding than techniques to prepare retinal slices, there are a few considerations to keep in mind with this method. First, the enzymes used for dissociating retinal tissue eventually degrade over time. If a piece of retina is not fraying during the trituration process, less active enzymes are the likely culprits. Next, the most favorable way to triturate a piece of retina is to position the barrel of the Pasteur pipet within $1 \mathrm{~mm}$ of the bottom of the microcentrifuge tube. This small gap allows the retinal tissue to move in and out of the pipet and be pulled apart, but without the tissue being sheared too strongly. Finally, it is important to allow the cells enough time to adhere to the perfusion chamber. Dissociated retinal cells, although attached to the concanavalin A or CellTak, can wash away if they are handled too soon. 
Table 2.18.1 Troubleshooting Guide for Tracking Quantum Dot-Tagged Calcium Channels

\begin{tabular}{|c|c|c|}
\hline Problem & Possible cause & Solution \\
\hline Few or no QDs present & $\begin{array}{l}\text { Too little antibody or QDs } \\
\text { were used on the preparation }\end{array}$ & $\begin{array}{l}\text { Increase the concentration of } \\
\text { either antibody or QDs }\end{array}$ \\
\hline $\begin{array}{l}\text { Too many cells are labeled } \\
\text { with QDs, and single particles } \\
\text { cannot be readily } \\
\text { distinguished }\end{array}$ & $\begin{array}{l}\text { Too much antibody or QDs } \\
\text { were used on the preparation }\end{array}$ & $\begin{array}{l}\text { Decrease the concentration of } \\
\text { either antibody or QDs }\end{array}$ \\
\hline QDs are clustered at the OPL & $\begin{array}{l}\text { The concentration of QDs is } \\
\text { too high or the QDs are older } \\
\text { than } 6 \text { months }\end{array}$ & $\begin{array}{l}\text { Decrease the concentration of } \\
\text { QDs or purchase a new stock } \\
\text { vial of QDs }\end{array}$ \\
\hline QDs are difficult to visualize & $\begin{array}{l}\text { QD visual spectra do not } \\
\text { match the filter cubes on the } \\
\text { microscopes settings and may } \\
\text { need to be adjusted on the } \\
\text { EMCCD }\end{array}$ & $\begin{array}{l}\text { Purchase QDs with spectra } \\
\text { matching the excitation and } \\
\text { emission of the microscope } \\
\text { filters; optimize the EMCCD } \\
\text { settings to amplify fluorescent } \\
\text { signals }\end{array}$ \\
\hline
\end{tabular}

\section{Anticipated Results}

\section{Synaptic attachment of QDs: Density and numbers}

The combination of antibody (rabbit anti$\alpha_{2} \delta_{4}$ antibody, 1:1000; biotinylated goat antirabbit antibody, 1:2000) and QD (20 nM) dilutions label approximately 2 to $20 \mathrm{Ca}_{\mathrm{V}}$ channels per retinal slice. We often see only 1 to 2 QDs in a microscope field. This is many fewer than the total number of $\mathrm{Ca}_{\mathrm{V}}$ channels on the retinal tissue, but the purpose of this technique is to label a handful of $\mathrm{Ca}_{\mathrm{V}}$ channels with QDs for SPT.

\section{Mobility behavior of membrane-embedded proteins}

Ultrastructural evidence suggests that $\mathrm{Ca}_{\mathrm{v}}$ channels straddle the base of the ribbon complex at photoreceptor synapses (Lasansky, 1973; Raviola and Gilula, 1975; tom Dieck et al., 2005). Our data suggest that photoreceptor $\mathrm{Ca}_{\mathrm{V}}$ channels, while mobile, remain in a confined domain near the synaptic ribbon. When plotted against measurement time interval, the MSD for a single QD-bound $\mathrm{Ca}_{\mathrm{v}}$ channel at a cone synapse reaches a plateau within only a few frames of imaging (Fig. 2.18.3B, black circles). The height of the plateau in the MSD profile provides a measure of the area of membrane in which movements of the $\mathrm{Ca}_{\mathrm{V}}$ channel are confined (Basic Protocol 3, step 9c; Saxton and Jacobson, 1997). Compared to an immobilized QD (Fig. 2.18.3B, squares), tagged $\mathrm{Ca}_{\mathrm{V}}$ channels exhibit significantly larger movements. To determine the diffusion coefficient, we measure the increase in
MSD over very short time intervals, in which channel movements are not yet confined, by using an acquisition rate of $15 \mathrm{msec} / \mathrm{image}$ (67 Hz; Basic Protocol 3, step 9b).

Measurements of the confinement domain of photoreceptor $\mathrm{Ca}_{\mathrm{V}}$ channels correlate well with ultrastructural dimensions of the synaptic ribbon (Mercer et al., 2011a). Plotting the $X$ and $Y$ coordinates obtained from QD imaging and SPT measurements can be used to correlate raw data with measurements of the confinement domain (Fig. 2.18.3). The movements of a channel in the lipid bilayer are necessarily constrained to two dimensions. Without the use of specialized techniques to track motion in the vertical axis (Watanabe et al., 2007; Huang et al., 2008; Shtengel et al., 2009; Park et al., 2012), it should be recognized that the confinement areas and diffusion coefficients are lower-bound estimates of the true values (Hall, 2008).

\section{Pharmacological manipulations}

Pharmacological manipulations that alter molecular interactions with a membranebound protein can serve two primary purposes. First, it can serve to validate the baseline biophysical properties of protein mobility characterized under baseline conditions. For example, if the QD has labeled a transmembrane protein, then disruption of actin should increase QD movements. More importantly, pharmacological agents can be used to elucidate underlying biological mechanisms. Notably, what types of molecular interactions regulate the diffusion rate and domain size of a
Imaging

2.18.19

Supplement 62 
given protein, channel, or receptor? For example, we hypothesized that the actin cytoskeleton and cholesterol microdomains regulated the lateral mobility of $\mathrm{Ca}_{\mathrm{V}} 1.4$ channels at photoreceptor synapses. In other retinal neurons, reciprocal interactions between $\mathrm{Ca}^{2+}$ influx and actin cytoskeleton dynamics have been reported (Job and Lagnado, 1998; Schubert and Akopian, 2004; Cristofanilli and Akopian, 2006; Cristofanilli et al., 2007). Thus, we predicted that pharmacologically disrupting the actin cytoskeleton would reduce $\mathrm{Ca}_{\mathrm{V}}$ channels interactions at the synapse and, in turn, increase the mobility of synaptic $\mathrm{Ca}_{\mathrm{V}}$ channels. Along the same lines, the membranes of rod and cone ribbon-style active zones are encircled by a layer of cholesterol (Cooper and McLaughlin, 1984). The physiological function of this lipid layer had not been directly probed, but we theorized that removing an active zone barrier in the presynaptic membrane would enhance the size of the confinement domain for a given $\mathrm{Ca}_{\mathrm{v}}$ channel.

To manipulate the actin cytoskeleton or membrane cholesterol, we bath-applied pharmacological reagents during the antibody labeling steps described in Basic Protocol 2. Cytochalasin D ( $20 \mu \mathrm{M}, 4 \mathrm{hr})$ was used to disrupt F-actin filaments, and methyl- $\beta$-cyclodextrin (10 mM, $1 \mathrm{hr}$ ), or the enzyme cholesterol oxidase $(2 \mathrm{U} / \mathrm{ml}, 1 \mathrm{hr}$ ) was used to deplete membrane cholesterol. In each instance, disruption of the cytoskeleton or removal of membrane cholesterol enhanced the size of the $\mathrm{Ca}_{\mathrm{V}}$ channel confinement domain in both retinal slices (Mercer et al., 2011a). Together, these findings suggest that molecular interactions between $\mathrm{Ca}_{\mathrm{V}}$ channels, actin, and cholesterol domains at photoreceptor synapses maintain the spatial integrity of $\mathrm{Ca}_{V}$ channels in the active zone.

\section{Time Considerations}

\section{Preparation of the Ambystoma tigrinum retinal model: Slices and dissociated neurons}

Preparation of retinal slices typically takes 30 to $45 \mathrm{~min}$ for experienced users. This includes preparation of the perfusion chamber, enucleating the eye, and isolating and cutting the retinal tissue. The dissociated retinal preparation typically takes around $90 \mathrm{~min}$. The surgical procedure is less demanding, but enzyme solutions must be made fresh before each experiment and enzyme incubation times must also be factored into this protocol.
Attaching QDs to synaptic $\mathrm{Ca}_{V}$ channels

As outlined in Basic Protocol 2, the antibody and QD binding steps are rather lengthy. We allow $3 \mathrm{hr}$ for attachment of the primary antibody, $1 \mathrm{hr}$ for the secondary antibody, and 15 min to attach QDs to the biotinylated secondary antibodies. Combined with the initial preparation of the retinal tissue, the total setup time including tissue preparation and QD binding is approximately 5 to $6 \mathrm{hr}$.

\section{QD imaging}

We have imaged QDs on retinal tissue for up to 3 to $4 \mathrm{hr}$ per experiment. The exact time varied day-to-day, depending on the number of QDs observed in a given preparation and the morphological health of the tissue. Healthy rods and cones appear true to their namesakes: the outer segments of rods are cylinders while the outer segments of cones taper into a fine point. Healthy cells are also translucent. We avoided photoreceptors that appeared damaged and unhealthy (i.e., the outer segments were sheared off or the cells were highly granular).

\section{SPT tracking analysis and statistical analysis}

Many software packages, including NISElements, now possess auto-track features for SPT that minimize the analysis time. However, because the software cannot always distinguish QD signals from other signals such as background fluorescence, the tracking results for each QD must be carefully inspected. With these considerations in mind, approximately 12 QD videos can be tracked and exported for statistical analysis within $2 \mathrm{hr}$.

\section{Retina immunohistochemistry}

Immunohistochemistry of retinal tissue is a multi-day process, with time needed for fixation, sectioning, antibody staining, and imaging. If performed sequentially, eyecups can be isolated, processed, and mounted for imaging in approximately $72 \mathrm{hr}$.

\section{Acknowledgements}

This research was supported by Research to Prevent Blindness, NIH grant EY10542 (W.B.T.), NIH grant EY1054214S1 (W.B.T.), UNMC Graduate Student Fellowship (A.J.M.), and NIH Training Grant T32-DK007245 (A.J.M.). We would also like to thank Dr. Ning Qin (Johnson \& Johnson Pharmaceuticals Research and Development) for providing the anti- $\alpha_{2} \delta_{4}$ antibody for our studies.

\section{Tracking Calcium Channel Movements}

2.18.20 


\section{Literature Cited}

Alcor, D., Gouzer, G., and Triller, A. 2009. Singleparticle tracking methods for the study of membrane receptors dynamics. Eur. J. Neurosci. 30:987-997.

Babai, N. and Thoreson, W.B. 2009. Horizontal cell feedback regulates calcium currents and intracellular calcium levels in rod photoreceptors of salamander and mouse retina. J. Physiol. 587:2353-2364.

Babai, N., Morgans, C.W., and Thoreson, W.B. 2010. Calcium-induced calcium release contributes to synaptic release from mouse rod photoreceptors. Neuroscience 165:1447-1456.

Bannai, H., Levi, S., Schweizer, C., Dahan, M., and Triller, A. 2006. Imaging the lateral diffusion of membrane molecules with quantum dots. Nat. Protoc. 1:2628-2634.

Bannai, H., Levi, S., Schweizer, C., Inoue, T., Launey, T., Racine, V., Sibarita, J.B., Mikoshiba, K., and Triller, A. 2009. Activity-dependent tuning of inhibitory neurotransmission based on GABAAR diffusion dynamics. Neuron 62:670682.

Bates, I.R., Hebert, B., Luo, Y., Liao, J., Bachir, A.I., Kolin, D.L., Wiseman, P.W., and Hanrahan, J.W. 2006. Membrane lateral diffusion and capture of CFTR within transient confinement zones. Biophys. J. 91:1046-1058.

Bauer, C.S., Tran-Van-Minh, A., Kadurin, I., and Dolphin, A.C. 2010. A new look at calcium channel alpha2delta subunits. Curr. Opin. Neurobiol. 20:563-571.

Bruchez, M. Jr., Moronne, M., Gin, P., Weiss, S., and Alivisatos, A.P. 1998. Semiconductor nanocrystals as fluorescent biological labels. Science 281:2013-2016.

Catterall, W.A. 2000. Structure and regulation of voltage-gated $\mathrm{Ca}^{2+}$ channels. Annu. Rev. Cell Dev. Biol. 16:521-555.

Chan, W.C. and Nie, S. 1998. Quantum dot bioconjugates for ultrasensitive nonisotopic detection. Science 281:2016-2018.

Charrier, C., Ehrensperger, M.V., Dahan, M., Levi, S., and Triller, A. 2006. Cytoskeleton regulation of glycine receptor number at synapses and diffusion in the plasma membrane. J. Neurosci. 26:8502-8511.

Choquet, D. 2010. Fast AMPAR trafficking for a high-frequency synaptic transmission. Eur. $J$. Neurosci. 32:250-260.

Cooper, N.G. and McLaughlin, B.J. 1984. The distribution of filipin-sterol complexes in photoreceptor synaptic membranes. J. Comp. Neurol. 230:437-443.

Cristofanilli, M. and Akopian, A. 2006. Calcium channel and glutamate receptor activities regulate actin organization in salamander retinal neurons. J. Physiol. 575:543-554.

Cristofanilli, M., Mizuno, F., and Akopian, A. 2007. Disruption of actin cytoskeleton causes internalization of $\mathrm{Ca}(\mathrm{v}) 1.3$ (alpha 1D) L-type calcium channels in salamander retinal neurons. Mol. Vis. 13:1496-1507.

Dahan, M., Levi, S., Luccardini, C., Rostaing, P., Riveau, B., and Triller, A. 2003. Diffusion dynamics of glycine receptors revealed by singlequantum dot tracking. Science 302:442-445.

Davies, A., Kadurin, I., Alvarez-Laviada, A., Douglas, L., Nieto-Rostro, M., Bauer, C.S., Pratt, W.S., and Dolphin, A.C. 2010. The alpha2delta subunits of voltage-gated calcium channels form GPI-anchored proteins, a posttranslational modification essential for function. Proc. Natl. Acad. Sci. U.S.A. 107:1654-1659.

Eggermann, E., Bucurenciu, I., Goswami, S.P., and Jonas, P. 2012. Nanodomain coupling between $\mathrm{Ca}(2)$ channels and sensors of exocytosis at fast mammalian synapses. Nat. Rev. Neurosci. 13:721.

Gomez-Varela, D., Kohl, T., Schmidt, M., Rubio, M.E., Kawabe, H., Nehring, R.B., Schafer, S., Stuhmer, W., and Pardo, L.A. 2010. Characterization of Eag1 channel lateral mobility in rat hippocampal cultures by single-particle-tracking with quantum dots. PLoS One 5:e8858.

Groc, L., Choquet, D., and Chaouloff, F. 2008. The stress hormone corticosterone conditions AMPAR surface trafficking and synaptic potentiation. Nat. Neurosci. 11:868-870.

Hall, D. 2008. Analysis and interpretation of twodimensional single-particle tracking microscopy measurements: Effect of local surface roughness. Anal. Biochem. 377:24-32.

Heine, M., Thoumine, O., Mondin, M., Tessier, B., Giannone, G., and Choquet, D. 2008. Activity-independent and subunit-specific recruitment of functional AMPA receptors at neurexin/neuroligin contacts. Proc. Natl. Acad. Sci. U.S.A. 105:20947-20952.

Huang, B., Wang, W., Bates, M., and Zhuang, X. 2008. Three-dimensional super-resolution imaging by stochastic optical reconstruction microscopy. Science 319:810-813.

Jakway, J.S. and Riss, W. 1972. Retinal projections in the tiger salamander, Ambystoma tigrinum. Brain Behav. Evol. 5:401-442.

Jares-Erijman, E.A. and Jovin, T.M. 2003. FRET imaging. Nat. Biotechnol. 21:1387-1395.

Job, C. and Lagnado, L. 1998. Calcium and protein kinase $\mathrm{C}$ regulate the actin cytoskeleton in the synaptic terminal of retinal bipolar cells. J. Cell Biol. 143:1661-1672.

Krizaj, D., Mercer, A.J., Thoreson, W.B., and Barabas, P. 2011. Intracellular pH modulates inner segment calcium homeostasis in vertebrate photoreceptors. Am. J. Physiol. Cell Physiol. 300:C187-197.

Kunz, W.S. and Kunz, W. 1985. Contribution of different enzymes to flavoprotein fluorescence of isolated rat liver mitochondria. Biochim. Biophys. Acta 841:237-246.

Lasansky, A. 1973. Organization of the outer synaptic layer in the retina of the larval tiger 
salamander. Philos. Trans. R. Soc. Lond. B Biol. Sci. 265:471-489.

Liu, S.L., Zhang, Z.L., Sun, E.Z., Peng, J., Xie, M., Tian, Z.Q., Lin, Y., and Pang, D.W. 2011. Visualizing the endocytic and exocytic processes of wheat germ agglutinin by quantum dot-based single-particle tracking. Biomaterials 32:76167624.

Mavrakis, M., Rikhy, R., Lilly, M., and LippincottSchwartz, J. 2008. Fluorescence imaging techniques for studying Drosophila embryo development. Curr. Protoc. Cell Biol. 39:4.18.14.18.43.

Medintz, I.L., Uyeda, H.T., Goldman, E.R., and Mattoussi, H. 2005. Quantum dot bioconjugates for imaging, labelling and sensing. Nat. Materials 4:435-446.

Mercer, A.J. and Thoreson, W.B. 2011. The dynamic architecture of photoreceptor ribbon synapses: Cytoskeletal, extracellular matrix, and intramembrane proteins. Vis. Neurosci. 28:453471.

Mercer, A.J., Chen, M., and Thoreson, W.B. 2011a. Lateral mobility of presynaptic L-type calcium channels at photoreceptor ribbon synapses. $J$. Neurosci. 31:4397-4406.

Mercer, A.J., Rabl, K., Riccardi, G.E., Brecha, N.C., Stella, S. L. Jr., and Thoreson, W.B. 2011 b. Location of release sites and calcium-activated chloride channels relative to calcium channels at the photoreceptor ribbon synapse. J. Neurophysiol. 105:321-335.

Mercer, A.J., Szalewski, R.J., Jackman, S.L., Van Hook, M.J., and Thoreson, W.B. 2012. Regulation of presynaptic strength by controlling $\mathrm{Ca} 2+$ channel mobility: Effects of cholesterol depletion on release at the cone ribbon synapse. $J$. Neurophysiol. 107:3468-3478.

Mikasova, L., Groc, L., Choquet, D., and Manzoni, O.J. 2008. Altered surface trafficking of presynaptic cannabinoid type 1 receptor in and out synaptic terminals parallels receptor desensitization. Proc. Natl. Acad. Sci. U.S.A. 105:1859618601.

Nachman-Clewner, M., St Jules, R., and TownesAnderson, E. 1999. L-type calcium channels in the photoreceptor ribbon synapse: Localization and role in plasticity. J. Comp. Neurol. 415:116.

Neher, E. and Sakaba, T. 2008. Multiple roles of calcium ions in the regulation of neurotransmitter release. Neuron 59:861-872.

Pang, J.J., Gao, F., Barrow, A., Jacoby, R.A., and Wu, S.M. 2008. How do tonic glutamatergic synapses evade receptor desensitization? $J$. Physiol. 586:2889-2902.

Park, H., Li, Y., and Tsien, R.W. 2012. Influence of synaptic vesicle position on release probability and exocytotic fusion mode. Science 335:13621366.

Probst, J., Dembski, S., Milde, M., and Rupp, S. 2012. Luminescent nanoparticles and their use for in vitro and in vivo diagnostics. Exp. Rev. Mol. Diagn. 12:49-64.
Qin, N., Yagel, S., Momplaisir, M.L., Codd, E. E., and D'Andrea, M.R. 2002. Molecular cloning and characterization of the human voltage-gated calcium channel alpha(2)delta-4 subunit. Mol. Pharmacol. 62:485-496.

Raviola, E. and Gilula, N.B. 1975. Intramembrane organization of specialized contacts in the outer plexiform layer of the retina: A freeze-fracture study in monkeys and rabbits. J. Cell Biol. 65:192-222.

Reed, M.A., Randall, J.N., Aggarwal, R.J., Matyi, R.J., Moore, T.M., and Wetsel, A.E. 1988. Observation of discrete electronic states in a zero-dimensional semiconductor nanostructure. Phys. Rev. Lett. 60:535-537.

Ribrault, C., Reingruber, J., Petkovic, M., Galli, T., Ziv, N.E., Holcman, D., and Triller, A. 2011. Syntaxin1A lateral diffusion reveals transient and local SNARE interactions. J. Neurosci. 31:17590-17602.

Saxton, M.J. 1997. Single-particle tracking: The distribution of diffusion coefficients. Biophys. J. 72:1744-1753.

Saxton, M.J. and Jacobson, K. 1997. Single-particle tracking: Applications to membrane dynamics. Annu. Rev. Biophys. Biomol. Struct. 26:373399.

Schubert, T. and Akopian, A. 2004. Actin filaments regulate voltage-gated ion channels in salamander retinal ganglion cells. Neuroscience 125:583-590.

Shtengel, G., Galbraith, J.A., Galbraith, C.G., Lippincott-Schwartz, J., Gillette, J.M., Manley, S., Sougrat, R., Waterman, C.M., Kanchanawong, P., Davidson, M.W., Fetter, R.D., and Hess, H.F. 2009. Interferometric fluorescent super-resolution microscopy resolves $3 \mathrm{D}$ cellular ultrastructure. Proc. Natl. Acad. Sci. U.S.A. 106:3125-3130.

Smith, A.M., Duan, H., Mohs, A.M., and Nie, S. 2008. Bioconjugated quantum dots for in vivo molecular and cellular imaging. Adv. Drug Deliv. Rev. 60:1226-1240.

Steele, E.C.,Jr., Chen, X., Iuvone, P.M., and MacLeish, P.R. 2005. Imaging of $\mathrm{Ca}^{2+}$ dynamics within the presynaptic terminals of salamander rod photoreceptors. J. Neurophysiol. 94:45444553.

Takagahara, T. 1987. Excitonic optical nonlinearity and exciton dynamics in semiconductor quantum dots. Phys. Rev. B Condens. Matter 36:9293-9296.

Thoreson, W.B. 2007. Kinetics of synaptic transmission at ribbon synapses of rods and cones. Mol. Neurobiol. 36:205-223.

Thoreson, W.B., Nitzan, R., and Miller, R.F. 1997. Reducing extracellular Cl- suppresses dihydropyridine-sensitive $\mathrm{Ca}^{2+}$ currents and synaptic transmission in amphibian photoreceptors. J. Neurophysiol. 77:2175-2190.

tom Dieck, S., Altrock, W.D., Kessels, M.M., Qualmann, B., Regus, H., Brauner, D., Fejtova, A., Bracko, O., Gundelfinger, E.D., and Brandstatter, J.H. 2005. Molecular dissection of the 
photoreceptor ribbon synapse: Physical interaction of Bassoon and RIBEYE is essential for the assembly of the ribbon complex. J. Cell Biol. 168:825-836.

Townes-Anderson, E., MacLeish, P.R., and Raviola, E. 1985. Rod cells dissociated from mature salamander retina: Ultrastructure and uptake of horseradish peroxidase. J. Cell Biol. 100:175188.

Van Hook, M.J. and Thoreson, W.B. 2012. Simultaneous whole cell recordings from photoreceptors and second-order neurons in an amphibian retinal slice preparation. J. Vis. Exp. e50007. http://www.jove.com/video/50007/.
Watanabe, T.M., Sato, T., Gonda, K., and Higuchi, H. 2007. Three-dimensional nanometry of vesicle transport in living cells using dual-focus imaging optics. Biochem. Biophys. Res. Commun. 359:1-7.

Wu, S.M. 1987. Synaptic connections between neurons in living slices of the larval tiger salamander retina. J. Neurosci. Methods 20:139-149.

Wycisk, K.A., Budde, B., Feil, S., Skosyrski, S., Buzzi, F., Neidhardt, J., Glaus, E., Nurnberg, P., Ruether, K., and Berger, W. 2006. Structural and functional abnormalities of retinal ribbon synapses due to Cacna2d4 mutation. Invest. Ophthalmol. Vis. Sci. 47:3523-3530. 